\title{
A PÓS-VERDADE É VERDADEIRA OU FALSA?
}

\author{
IS THE POST-TRUTH TRUE OR FALSE?
}

¿ES LA POSVERDAD O FALSA?

\section{Adilson Cristiano Habowski ${ }^{1}$; Elaine Conte ${ }^{2}$; Carla Milbradt ${ }^{3}$}

RESUMO

Trata-se de uma resenha crítica do livro "A pós-verdade é verdadeira ou falsa?".

PALAVRAS-CHAVE: Pós-verdade. Bolhas. Notícias falsas.

ABSTRACT

It is a critical review of the book "Is the posttruth true or false?".

KEYWORDS: Post truth. Bubbles. Fake news.

RESUMEN

Es una revisión crítica del libro "¿La verdad es falsa o verdadera?"

PALAVRAS-CLAVE: Posverdad. Burbujas. Noticias falsas.

\section{SANTAELLA, Lucia. A Pós-Verdade é verdadeira ou falsa? Barueri, SP: Estação das Letras e Cores, 2019. 98p.}

As origens e rumores da pós-verdade surgem num momento caracterizado pela abertura e democratização do consumo de produtos, serviços e informações pela internet. A pós-verdade é verdadeira ou falsa?, de Lucia Santaella ${ }^{4}$, chama a atenção para os desafios da incorporação de três novas palavras - bolhas, notícias falsas e pós-verdade. A autora discute a complexidade da explosão digital que afeta todas as dimensões humanas e relações de interesses políticos e mercadológicos, apresentando uma obra dividida em seis capítulos, abordando tais metamorfoses e tendências superficiais em suas inter-relações pessoais, culturais e sociais. Os argumentos mobilizados pela autora nos ajudam a compreender que as

\footnotetext{
${ }^{1}$ Mestre em Educação - Universidade La Salle (UNILASALLE). Canoas, RS - Brasil. Professor de Ensino Religioso do Colégio Salesiano Dom Bosco. Canoas, RS - Brasil. E-mail: adilsonhabowski@hotmail.com

2 Doutora em Educação - Universidade Federal do Rio Grande do Sul (UFRGS). Porto Alegre, RS - Brasil. Professora da Universidade La Salle (UNILASALLE). Canoas, RS - Brasil. E-mail: elaine.conte@unilasalle.edu.br

${ }^{3}$ Mestranda em Educação - Universidade La Salle (UNILASALLE). Canoas, RS - Brasil. E-mail: cal milbradt@hotmail.com

${ }^{4}$ Lucia Santaella é uma das principais pensadoras da semiótica e do pensamento de Charles Peirce no Brasil. Submetido em: 15/11/2019 - Aceito em: 25/03/2020
}

(C) ETD-Educação Temática Digital Campinas, SP $\quad$ v.22 $\quad$ n.2 $\quad$ p. 492-497 abr./jun.2020


informações mentirosas tendem a desagregar os sujeitos e tornar invisível a humanidade, isolando os contextos da própria experiência do mundo real e os apelos da comunidade.

O primeiro capítulo aborda 0 que as bolhas ${ }^{5}$ ocultam e o que elas são. Santaella (2019) diz que a personalização feita por filtros de máquinas de buscas ou mídias sociais promove segregação ideológica, tendenciosidades e reverbera no coletivo, porque torna as pessoas vulneráveis a manipulações, frequentemente a serviço de interesses unilaterais, com propagandas e fechamento dos usuários em bolhas de informações, estreitando visões de mundo. A invisibilidade de tais mecanismos empregados por poderosas companhias de tecnologia tem seu design destinado a retratar a própria bolha de desejos e crenças a que pertencemos. Trata-se de uma questão paradoxal, pois a retroalimentação de ideias cria um solo fértil para a polarização de opiniões desinformadas e radicais. Quando recebemos informações que confirmam as nossas crenças automaticamente rejeitamos tudo o que rompe com nossos hábitos de agir e de pensar diferente, criando nossas próprias bolhas. Alerta que notícias buscadas nas mídias sociais podem conter mais riscos de recair nas bolhas coletivas e no fortalecimento de preconceitos. Embora haja um efeito democratizante destas buscas para expandir gostos musicais ou livros, elas também são classificadas por conteúdos parciais (de algoritmos, softwares e inteligência artificial) e baseadas na popularidade para fins mercadológicos. Em tempos de desinformação, em que a verdade do cotidiano perde sua validade, a educação também é ameaçada e mostra reflexos pela falta de ação coordenada ou reflexão dos professores, especialmente quando recebem livros didáticos novos com informações falsas, descontextualizadas ou equivocadas. Aliás, o enfrentamento da desinformação manifesta-se no debate coletivo da sala de aula e na análise da realidade, só assim recuperamos a dimensão formativa e humanizadora da educação, resistindo às dissimulações da vida.

Muito depende da compreensão, das formas de filtragem e aprendizagem do usuário, ou seja, de "uma formação educacional segura que o habilite a colocar seus preconceitos à prova" (p. 21). Os projetos nesse sentido precisam oferecer caminhos de pesquisa às novas gerações para que se tornem encorajadas a pensar criticamente acerca dos conteúdos e informações (visões extremistas, injustas, violências simbólicas e ofensivas), tornando-as "resilientes e empoderadas com as habilidades, o conhecimento e o suporte que as auxiliarão a navegar tão seguramente quanto possível. Essa é a tarefa da educação para e nas redes", além de ser um problema e uma exigência para a vida em sociedade (p. 27). A formação

\footnotetext{
5 "O nome filter bubbles (bolhas-filtro, bolhas de filtro, que prefiro chamar de bolhas filtradas) foi cunhado pelo ativista da internet Eli Pariser por volta de 2010 e discutido no seu livro best seller com esse mesmo nome, em 2011, portanto, cinco anos antes dos dois acontecimentos que chacoalharam o mundo: a eleição de Trump e o Brexit no Reino Unido. [...] dada a aceleração temporal do mundo das redes, a passagem de cinco anos deve corresponder mais ou menos à passagem de 25 anos, antes das redes" (p.13).
}

(C) ETD- Educação Temática Digital Campinas, SP $\quad$ v.22 $\quad$ n.2 $\quad$ p. 492-497 abr./jun.2020


classes.

A descentralização da informação e as tendências propagandísticas ideológicas, sem compromisso com a verdade dos fatos, criam o ceticismo generalizado e o sentimento de desconfiança do público em relação às instituições democráticas ou às divulgações do conhecimento científico, num clima de anti-intelectualismo e de pensamento anticientífico. Em situações em que a veracidade dos fatos é o que menos importa, provocando crises de valores e conversações polarizadas, é preciso desmascarar os véus de fumaça, os ambientes tóxicos, competitivos e a pulverização desses sites ou posts, averiguando os interesses que estão em jogo. Com base em resultados de estudos, a autora defende que é preciso discutir para aprender na direção da compreensão dos participantes.

Aponta que para se compreender minimamente de onde vêm as atuais controvérsias é preciso rever A estrutura das revoluções científicas, de Thomas Kuhn (2012), pois antes dele a ciência era concebida como reunião de fatos, teorias e métodos e a obra de Kuhn vai se insurgir contra a visão linear e progressiva da ciência. Parece que vivemos em um período no qual os fatos não existem em si, mas são construídos por comunidades desconfiadas dos cientistas. O debate traz uma entrevista recente sobre o tema com Bruno Latour, afirmando "que é preciso reganhar a autoridade da ciência. Na situação atual, os cientistas devem reaver sua respeitabilidade [e] isso ainda implica apresentar a ciência em ação", para não recairmos em máscaras de um poder distorcido da produção de conhecimento (p. 58). A educação implica no movimento constante de revisão, (auto)crítica e reflexão sobre as próprias ações e palavras do mundo comum, uma vez que são saberes narrados na vida em sociedade e transmitidos às próximas gerações. A educação é um fenômeno humano fundamental para a resistência à mentira, que falseia a realidade e intenta o apagamento da história.

O capítulo 4 aborda A reivindicação da verdade no jornalismo, diante da torrente de notícias enganadoras de conteúdos maliciosos (disinformation), justamente para enfrentar a ingenuidade daqueles que as sustentam. Para Arendt (2005), a verdade dos fatos não está segura nas mãos do poder quando a mentira se insere na política de direitos humanos. Contudo, está se tornando cada vez mais difícil distinguir entre fato e opinião nas redes sociais com uma lógica semiótica em intercursos comunicacionais, vaguezas e indeterminações que derivam do real com uma mutabilidade constante. "Mas a linguagem só funciona como tal quando encontra um intérprete responsável por um ato interpretativo que instaura uma relação comunicativa" (p. 68). A educação é ameaçada por violências e mentiras não apenas no que diz respeito à verdade dos fatos, conhecimentos e a sua justificação, mas ela aparece inscrita em livros didáticos esvaziados de sentido, legitimando os mecanismos de reprodução da indústria cultural à obtenção de resultados instrumentais e superficialmente eficientes.

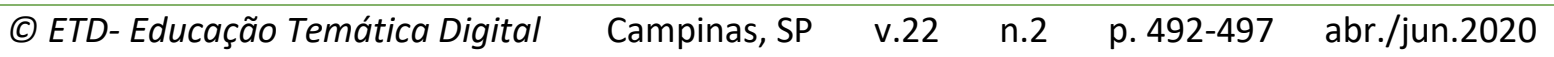


O capítulo 5 - A verdade fatual e o jornalismo inicia com a questão da verdade e da política por dois eixos principais (a. verdade racional e factual; b. verdade e opinião), de Hannah Arendt (2005). Arendt quer descobrir os danos que o poder político é capaz de infligir à verdade racional - produzida pela mente humana na matemática, ciência, filosofia, arte e literatura, e à verdade factual, "que está mais sujeita aos assédios do poder", como o jornalismo (p. 71). Arendt sequer imaginou a que ponto a mentira organizada entraria em pauta hoje, com as redes sociais atuando contra a verdade factual. "Mas afinal, o que é verdade factual? Podem os fatos existirem independentes da intepretação e da opinião? Arendt está ciente da impossibilidade da determinação dos fatos sem interpretação", daí a tarefa do jornalismo é de trazê-los à luz por meio de interpretações (p. 73).

Na verdade, quanto mais complexos os fatos mais eles podem ser manipulados até se converterem em mentiras e distorções. "Para Arendt, os fatos são contingentes porque poderiam sempre ter sido diferentes. Mas, uma vez dada a ocorrência, trata-se de fait accompli (fato consumado). Não há como mudar o passado a bel prazer a não ser pela mentira ou pelas falhas da memória", mas a verdade dos fatos deve ser buscada sempre (p. 74). A autora problematiza que a verdade factual hoje é mais vulnerável a falsificações e manipulações do que a verdade racional, isso porque, poder e fatos convivem no mesmo domínio da realidade e do registro ou não dos fatos. Os conflitos, oposições e complementaridades entre jornalismo e política estão sendo levadas e dissolvidas em bolhas e fake news, "em prol da disseminação de crenças enrijecidas por ideias fixas e inflexíveis, trabalham para minar a confiabilidade de quaisquer fontes de registros e transmissão da efetiva ocorrência dos fatos" (p. 80).

No último capítulo denominado Outras verdades, a autora retoma Hannah Arendt para arrebatar o leitor reafirmando que "entre os modos existenciais de dizer a verdade sobrelevam-se a solidão do filósofo, o isolamento do cientista e do artista, a imparcialidade do historiador e do juiz e a independência do descobridor de fatos, da testemunha e do relator" (p. 81). Tudo isso para mostrar que de uma forma ou de outra, nos contextos da ciência, da filosofia e da arte, somos responsabilizados a nos justificar pela verdade dos fatos, por métodos e formas de conhecimento estabelecidas epistemologicamente. "Não há dúvida de que existem pseudociências, isto é, procedimentos, discursos e crenças que pretendem se fazer passar por ciência, [ou] invasões no território da ciência, como aquelas que se dão em práticas ilegítimas de publicação e confiabilidade da produção", assim como surgem investigações com resultados maquiados e produtivismos (p. 83-84). A autora deixa claro que as ondas da pós-verdade não estão deixando ilesas as áreas humanas, atingindo, questões científicas com falsas crenças tais como do terraplanismo e do criacionismo. Entretanto, justifica que tais crenças não "atingem o fazer da ciência para o qual não cabe a pecha de pósverdade. Por que não? Pelo simples fato de que a ciência não trabalha com verdades

$\begin{array}{llllll}\text { (C) ETD-Educação Temática Digital } & \text { Campinas, SP } & \text { v.22 } & \text { n.2 } & \text { p.492-497 } & \text { abr./jun.2020 }\end{array}$


indiscutíveis, mas discutíveis", provisórias e questionáveis porque alimentadas na reflexão, linguagens, leituras, diálogos sensíveis acerca da realidade e em confronto com o outro ( $p$. 84).

A autora desenvolve um trabalho sensível e nos convida à reflexão sobre questões contemporâneas da pós-verdade em meio à indeterminação e ambiguidades dos fenômenos da linguagem na cultura virtual, projetando a necessidade de regeneração da sensibilidade, da arte de educar, da literatura, da música e da poesia, para criar condições de possibilidade a um olhar (auto)crítico frente as novas manifestações. A autora discute à luz da questão da pós-verdade, que a educação é a melhor barreira de proteção às bolhas, falsificações de notícias e outras formas de ignorância em ação, porque busca em seus princípios culturais a veracidade dos fatos e conhecimentos. A obra contribui com o alerta à cega disseminação de preconceitos e violências, para que os processos educativos sirvam ao discernimento crítico dos discursos, à contradição e à diferença, como forma de coordenar as diferentes leituras de mundo, em diálogo com as tradições democráticas. Um sentido posto em palavras requer a produção da intersubjetividade mesmo em condições transitórias, para promover a pluralização de formas e estilos de vida.

\section{REFERÊNCIAS}

ARENDT, Hannah. Entre o passado e o futuro. 5. ed. São Paulo: Perspectiva, 2005.

IRETON, Cherilyn; POSETTI, Julie (Org.). Jornalismo, fake news \& desinformação: manual para educação. Paris: Unesco, 2018.

KUHN, Thomas. The structure of scientific revolutions. $4^{\text {th }}$.ed. United States: The Univ. of Chicago, 2012.

Revisão gramatical realizada por: Maria Edilene de Paula Kobolt.

E-mail: mariaedilenekobolt@gmail.com 